\title{
A FLEXIBILIZAÇÃO COMO UM IMPERATIVO POLÍTICO NAS POLÍTICAS CURRICULARES PARA O ENSINO MÉDIO NO BRASIL: UMA LEITURA CRÍTICA
}

\author{
LA FLEXIBILIZACIÓN COMO UN IMPERATIVO POLITICO EN LAS \\ POLÍTICAS CURRICULARES PARA LA ENSEÑANZA MEDIA EN BRASIL: \\ UNA LECTURA CRÍTICA
}

\begin{abstract}
FLEXIBILIZATION AS A POLITICAL IMPERATIVE IN CURRICULAR POLICIES FOR HIGH SCHOOL IN BRAZIL: A CRITICAL READING
\end{abstract}

Emerson Lizandro Dias SILVEIRA ${ }^{1}$

Roberto Rafael Dias da SILVA ${ }^{2}$

RESUMO: O presente artigo inscreve-se no campo dos Estudos Curriculares e realiza uma análise preliminar da reforma curricular do Ensino Médio promulgada no Brasil em 2017. A partir de uma análise teórico-conceitual que toma como base as políticas educacionais no contexto da Globalização e a Lei n. 13.415/2017, o objetivo do trabalho é compreender que racionalidades políticas se constituem no Brasil, desde a década de 1990, que reorientam e reproduzem arranjos curriculares de forma contínua e progressiva. O estudo justifica-se pela centralidade que o Ensino Médio tem assumido na agenda educacional brasileira no decorrer deste período e que neste momento volta à tona com a recente reformulação.

PALAVRAS-CHAVE: Políticas curriculares. Ensino médio. Reestruturação capitalista.

RESUMEN: El presente artículo se inscribe en el campo de los Estudios Curriculares y examina la reforma curricular de la Enseñanza Media promulgada en 2017. A partir de un análisis teórico conceptual que tiene como base las políticas educativas en el contexto de la Globalización y la ley 13.415 / 2017, el objetivo Del trabajo es entender que las racionalidades políticas se constituyen en Brasil, desde la década de 1990 que reorientan y reproducen arreglos curriculares de forma continua y progresiva. El estudio se justifica por la centralidad que la Enseñanza Media ha asumido en la agenda educativa brasileña

PALABRAS CLAVE: Políticas curriculares. Enseñanza media. Reestructuración capitalista

\footnotetext{
${ }^{1}$ Universidade do Vale do Rio dos Sinos (UNISINOS), São Leopoldo - RS - Brasil. Doutorando do PPG em Educação/UNISINOS. ORCID: <http://orcid.org/0000-0002-6432-873X>. E-mail: emersongeors@gmail.com

${ }^{2}$ Universidade do Vale do Rio dos Sinos (UNISINOS), São Leopoldo - RS - Brasil. Professor doutor em Educação do PPG em Educação/UNISINOS. ORCID: <http://orcid.org/0000-0001-6927-3435>. E-mail: robertods@unisinos.br
} 
ABSTRACT: This article is part of the Curricular Studies field and examines the curricular reform of the Secondary School promulgated in 2017. Based on a theoretical conceptual analysis based on educational policies in the context of Globalization and Law 13.415 / 2017, the objective Of the work is to understand that political rationalities are constituted in Brazil, since the 1990s that reorient and reproduce curricular arrangements in a continuous and progressive way. The study is justified by the centrality that High School has assumed in the Brazilian educational agenda since the 1990s and that at this moment comes back to the surface with the recent reformulation.

KEYWORDS: Curricular policies. Secondary education. Capitalist restructuring

\section{Introdução}

O Ensino Médio, última etapa da educação básica no sistema educacional brasileiro, vem desde a promulgação da Lei de Diretrizes e Bases da Educação Nacional de 1996 sofrendo significativas reformulações no que tange a sua organização curricular, objetivos, estrutura e arranjos pedagógicos (KRAWCZYK, 2011). Estas reformulações são instituídas a partir do embate entre diferentes ideologias, valores e interesses dos distintos atores da sociedade brasileira. Estes atores podem ser assim identificados: por um lado, a sociedade civil - entidades ligadas à Educação - que vem tentando se manifestar apresentando propostas que respondam aos problemas enfrentados pela escola; de outro lado, o Ministério da Educação que veio, sistematicamente, incorporando ideias postuladas pelos organismos internacionais, tais como UNESCO, FMI, BANCO MUNDIAL, que preconizam a adaptação dos sistemas e currículos escolares das sociedades em desenvolvimento aos interesses e lógicas do mercado.

Assim sendo, o objetivo que orienta este trabalho é descrever e problematizar os modos pelos quais a lógica de flexibilização curricular no Ensino Médio, ainda que produzida a partir dos anos de 1990, recebeu ênfases distintas nas últimas décadas, culminando na reforma curricular promulgada em fevereiro de 2017 pelo Ministério da Educação no contexto brasileiro. Procurar-se-á apresentar os vínculos existentes entre o que propõe a reforma e o contexto político e econômico internacional, o qual foi redimensionado a partir das mudanças produtivas em curso no final do último século. Essa vinculação está presente na finalidade assumida pelos documentos oficiais em relação à Educação escolar, especificamente no escopo deste artigo na organização curricular proposta para o Ensino Médio. Será analisada a flexibilização curricular 
presente nas contínuas diretrizes que são promulgadas a partir dos anos de 1990: resoluções CEB nº 04/2010, CEB Nº 02/2012 e Lei 12.345/2017.

\section{Contexto educacional e as relações políticas e econômicas após 1990}

O contexto atual é marcado pelo agravamento de crises generalizadas nas mais diversas esferas sociais do mundo, acarretando incertezas e imprevisibilidades, decorrentes, muitas vezes, da multiplicidade de sentidos em disputa, o que "incute em praticamente todas as realidades preexistentes novos significados, outras conotações" (IANNI, 1995, p. 163). O campo educacional, por situar-se numa área de interações e de influências, representa um espaço de interesses e impasses políticos e econômicos, os quais colocam a educação em um terreno movediço (POPKEWITZ, 2000).

Estes interesses materializam-se a partir de determinadas matrizes discursivas que tendem a alojar-se no sistema educacional, sobretudo no campo das políticas educacionais, ampliando sua legitimidade e amplitude. Neste sentido, pensar sobre a educação na atualidade requer um entendimento de um contexto político e econômico marcado por uma revolução tecnológica sem precedentes. Alguns pesquisadores a chamam de "informacional ou técnico-científica" (SANTOS, 1996), outros seguindo uma lógica cronológica como “Terceira Revolução Industrial” (HARVEY, 1993). Qualquer que seja a definição em voga, o fato a destacar é que o momento que atravessamos é marcado por inúmeras transformações no espaço geográfico, nas relações sociais, culturais e políticas.

Essas transformações promovidas no interior das formas capitalistas contemporâneas sobre a estrutura social de inúmeros países gerou um importante debate que busca reconceitualizar as novas sociedades. Tomando-se como principal referência as transformações tecnológicas promovidas pelo Capitalismo Globalizado e a crescente exigência de conhecimentos nas tarefas realizadas pelos trabalhadores, ganhou importância o conceito de "Sociedade Pós-Industrial" definido na década de 1970 por Daniel Bell (1973). De acordo com o sociólogo, estaríamos entrando em uma fase de sociedade "pós-industrial" ao afirmar que as atividades produtivas (industriais) estariam sendo substituídas pelas atividades de serviços, assim como, no século passado, teria havido a substituição da agricultura pela indústria. Através dessa dicotomia simplificada, o autor argumenta que a sociedade pós-industrial se fundaria nos serviços 
e o seu motor básico seria a informação, e não mais o trabalho produtivo, baseado no trabalho braçal do setor industrial.

Para Bell (1973), a sociedade pós-industrial representaria a superação da habilidade (o saber-fazer) pela centralidade do conhecimento como exigência para a inserção neste tipo de sociedade. Ao forjar este conceito ainda na década de 1960, o autor pretendia dar visibilidade às profundas transformações que o sistema capitalista vinha sofrendo desde metade do século XX.

\begin{abstract}
A noção de sociedade pós-industrial, assim como a de sociedade industrial ou de capitalismo, só tem significado como esquema conceitual. Essa noção identifica um novo princípio axial de organização social e define um núcleo comum de problemas que as sociedades que vão adquirindo um caráter pós-industrial cada vez mais acentuado terão de enfrentar. O conceito de pós industrialismo representa um esforço no sentido de identificar uma mudança na estrutura social. Mas não existe uma correlação obrigatória, como tenho insistentemente afirmado, entre as modificações neste domínio, ao contrário das modificações nas outras duas dimensões analíticas de uma sociedade: a da política e da cultura. (BELL, 1973, p. 136)
\end{abstract}

Partindo dessa definição central para o diagnóstico proposto por Bell, torna-se pertinente afirmar, em nossa perspectiva, a existência de um forte vínculo entre as mudanças nos processos de produção e sua interferência direta sobre a produção de conhecimento e as consequentes reformas educacionais as quais os países ocidentais, neste caso especificamente o Brasil passaram a ter ao longo da segunda metade do século XX (SFREDO; SILVA, 2016).

Ao definir conceitualmente este período histórico como sociedade pós-industrial, Bell (1973) utilizou em sua abordagem teórica a constituição de "cinco princípios axiais", quais sejam: a passagem da produção de bens à produção de serviços; o aumento de importância dos técnicos e profissionais liberais em detrimento da classe operária; a ascensão do papel das ideias e do saber teórico; o primado pela gestão do desenvolvimento técnico, para além de indivíduos e nações e, por último e central, o princípio da tecnologia intelectual, ou inteligência artificial, liberando o homem de tarefas físicas e também de certos esforços intelectuais. Seus pressupostos teóricos, em linhas gerais, podem ser identificados como a primeira expressão do termo sociedade do conhecimento tão propagado a partir da década de 1990: conhecimento como princípio axial; a universidade como lócus privilegiado da produção do conhecimento, conhecimento e tecnologia como os novos fatores produtivos e de inovação, o indivíduo 
definindo sua posição social por mérito, relações entre economia e política reconhecidas pelo mérito.

Dito isso, podemos vincular as questões diagnosticadas por Bell (1973) aos posicionamentos e diretrizes que passam a dominar os discursos e as agendas estatais que passam a situar a escola como um espaço de produção de conhecimentos para o desenvolvimento nacional (SFREDO; SILVA, 2016; RAMOS, 2011). Adota-se, a partir desse cenário, determinados mecanismos que levam a adequação dos sistemas de ensino a essa nova conjuntura econômico social que emerge a partir da década de 1960. A seguir, na próxima seção, tomaremos como alvo a descrição das novas políticas curriculares e diretrizes do ensino no contexto da globalização.

\section{As políticas curriculares e as diretrizes de ensino no contexto da Globalização}

As transformações operadas no contexto das relações produtivas no período posterior 2a Guerra Mundial, definida por Daniel Bell como "pós-industrialismo", sinaliza para a reestruturação do capital produtivo em torno de novas lógicas industriais que desencadeariam a chamada revolução técnico-científica-informacional, indicando a continuidade do processo histórico de mundialização do Capitalismo iniciado na Modernidade e acelerado a partir da intensa escalada da industrialização e da expansão do setor de serviços e comunicações. Nesse sentido Harvey (2006, p. 80) aponta que:

O capitalismo tem recorrido repetidas vezes à reorganização geográfica [...] como solução parcial para suas crises e seus impasses. Assim, ele constrói e reconstrói uma geografia à sua própria imagem e semelhança. Constrói uma paisagem geográfica distintiva, um espaço produzido de transporte e comunicações, de infraestruturas e de organizações territoriais que facilita a acumulação do capital numa dada fase da história, apenas para ter de ser desconstruído e reconfigurado a fim de abrir caminho para uma maior acumulação num estágio ulterior.

Essa reorganização espacial sugerida por Harvey é decorrente da própria dinâmica de acumulação do Capitalismo que se reconfigura sempre com a intenção de abrir caminho para uma maior acumulação numa fase posterior, a qual Castells (1999) e Santos (1999) definem como Globalização. Na ótica desses autores, esta expressão é recente, forjada no ocaso da Guerra Fria, mas seu significado acompanha a evolução do sistema capitalista desde a expansão marítima comercial empreendida pelo continente 
europeu no século XV em busca de novos mercados. O desenvolvimento do modo de produção capitalista de produção, em forma extensiva e intensiva, reorganiza-se com base em novas tecnologias, criação de novos produtos, recriação da divisão internacional do trabalho e mundialização de mercados. As forças produtivas básicas, compreendendo o capital, a tecnologia e a força de trabalho, superam fronteiras geográficas, históricas e culturais, multiplicando-se assim as suas formas de articulação e contradição. Conforme Santos (1999, p. 115), "uma nova combinação de fatores, diferente da que comandava o sistema anterior, vai ter um papel fundamental no sistema novo".

Esse novo momento que o autor sinaliza tem suas raízes no período subsequente à Segunda Guerra Mundial, quando se deram as principais descobertas tecnológicas em eletrônica, o primeiro computador programável e o transistor, fonte da microeletrônica, o verdadeiro cerne da revolução da tecnologia da informação do século XX. No entanto, é somente na década de 1970 que as novas tecnologias de informação difundiram-se amplamente, acelerando seu desenvolvimento e convergindo-se num novo paradigma. Esse é um evento histórico da mesma importância da Revolução Industrial do século XVIII, induzindo um padrão de descontinuidade nas bases materiais da economia, da sociedade e da cultura. Santos (1999) alerta que, diante das características atuais emanadas das transformações nas sociedades e no espaço geográfico devem ser entendidas a partir do conhecimento de três dados típicos de nossa época: a unicidade técnica (difusão em escala planetária de técnicas produtivas), a convergência dos momentos (a simultaneidade das relações), e a unicidade do motor (interdependência econômica).

Esses três dados formam a materialização da Globalização das relações econômicas que passam a gerar eventos que são interdependentes num grande circuito global de relações (SANTOS, 1996). Neste contexto, destaca-se que se faz parte de um processo de integração mundial, o qual se intensifica a cada instante, tendo em vista que "o processo de globalização acarreta a mundialização do espaço geográfico" (SANTOS, 1996, p. 34). Consequentemente, ocorre a subordinação dos espaços nacionais aos interesses internacionais. Para o mesmo autor, a ciência, a tecnologia e a informação são a base para a apropriação do espaço, sendo mais favorável na sua acepção, "aos interesses dos atores hegemônicos da economia e da sociedade".

O desenvolvimento tecnológico propiciado pelo avanço da ciência e da microeletrônica acentuado a partir dos anos de 1970 (HARVEY, 2006), passa a impor 
um novo padrão de desenvolvimento, denominado acumulação flexível, gerando um processo de reestruturação industrial baseado em novos processos produtivos, orientando a reestruturação produtiva em direção a um modelo de produção flexível e a novas formas de organização da produção adotando a partir daí novas práticas gerenciais diante da acirrada concorrência e da abertura da economia (ANTUNES; PINTO, 2017).

A forte influência de fatores econômicos, da velocidade do progresso científicotecnológico, da transformação do processo de produção e de fatores sociais, políticos e outros, tornam o conhecimento rapidamente superado, exigindo novos modelos de gestão nas organizações, no sentido de serem mais competitivas no mercado globalizado. Estando a sociedade dominada pelas exigências do capital, o processo de reestruturação produtiva traz inúmeras consequências para o mundo do trabalho e para o âmbito do desenvolvimento das políticas sociais. As políticas públicas passam a ser norteadas e alinhadas ao crescimento econômico, daí ser impossível tratar das políticas educacionais sem que a análise deixe de considerar o contexto sócio-econômico. Nessa perspectiva, o estabelecimento de políticas educacionais de cunho reformador é oriundo das relações sociais advindas do processo produtivo assumidas pelo modelo capitalista de produção (POPKEWITZ, 2000).

Sob um prisma curricular, Popkewitz (1997), atenta que desde a partir da década de 1990, os diversos elementos produtores de poder (Estado, empresas, dentre outros) têm fixado na retórica das reformas educativas. Mais do que um processo formal, o discurso de reforma deve ser considerado como um elemento integral dos fatos e acordos estruturados da escolarização com o intuito de alinhar as necessidades econômicas emergentes a uma escolarização capaz de se organizar em torno desta perspectiva. Saviani (2002), de outra perspectiva, ao analisar o papel do Estado nesta conjuntura, oferece contribuições importantes ao salientar que:

[...] sob a inspiração do toyotismo, busca-se flexibilizar e diversificar a organização das escolas e o trabalho pedagógico, assim como as formas de investimento(...) o Estado, agindo em consonância com os interesses dominantes, a transfere responsabilidades, sobretudo no que se refere ao financiamento dos serviços educativos, mas concentra em suas mãos as formas de avaliação institucional. Assim, também na educação, aperfeiçoando-se os mecanismos de controle, inserindo-a no processo mais geral de financiamento das crises no interesse da manutenção da ordem vigente (p. 23). 
A inserção positiva das políticas educacionais neste cenário poderia estar diretamente relacionada à adoção de um novo modelo produtivo centrado na flexibilização. Tal modelo, combinando custos mínimos e eficiência máxima, deve elevar a qualidade dos produtos e serviços e possibilitar a prática de preços competitivos. A educação passa a ser fundamental para a formação de trabalhadores responsáveis, eficientes, informados e autônomos, capazes de contribuir para o desenvolvimento de seu Estado e país, garantindo competitividade ao setor industrial e de serviços (ANTUNES; PINTO, 2017).

A inclusão da educação como serviço semelhante aos oferecidos pelo grande mercado explicita também um outro aspecto importante acerca das reformas curriculares em curso no Brasil, a partir dos anos de 1990, qual seja: a avaliação educacional. Conforme Ball (2011), nos últimos anos agências internacionais como o Banco Mundial e a OCDE tem atribuído enorme importância à avaliação em larga escala, tendo em vista sua força no sentido de impulsionar reformas educativas.

Emerge deste pressuposto certa discursividade, direcionada para o sentido de formar especialistas locais, elaborar receituários, conceitos, metodologia e indicadores adequados a servir a este modelo (TEODORO, 2011; BALL, 2011). No caso do Banco Mundial, percebe-se explícita relação entre avaliação e financiamento, fomentando com estas avaliações características de controle e uma pedagogia de avaliação.

Nesta direção, atentamos que Ball (2011) caracteriza as reformas em educação como um evento em cadeia, que atingiu em distintos espaços do sistema mundial, governos de países com histórias e culturas distintas, com realidades socioeconômicas muito diferenciadas, tornando-se uma verdadeira obsessão dos governos. Os constantes empreendimentos, estudos e publicações das organizações internacionais corroboram para,

[...] um decisivo papel na normalização das políticas educativas nacionais, estabelecendo uma agenda que fixa não apenas as prioridades, mas igualmente as formas como os problemas se colocam e equacionam, e que constituem uma forma de fixação de um mandato, mais ou menos explícito conforme a centralidade dos países. (TEODORO, 2001, p. 128).

O sistema educacional brasileiro, influenciado por esse feixe de mudanças, recebeu grandes transformações na última década do século $\mathrm{XX}$, influenciadas pelo movimento de mudanças no modo de acumulação capitalista. Nesse movimento, o 
mercado passou a ser o elemento balizador, servindo de parâmetro regulador das esferas de organização social. A valorização do mercado como regulador dos setores sociais decorre da intensificação do processo de globalização econômica, processo fortalecido pelo intercâmbio comercial, e que influencia o modelo produtivo alterando gradativamente as relações de trabalho e as exigências ao trabalhador (ANTUNES; PINTO, 2017). A busca por maior eficiência e manutenção do nível de competitividade impôs constante readequação da atividade produtiva às quais se incorporam os avanços tecnológicos. Este processo gradativamente reformula a atividade do trabalho e exige do trabalhador novas habilidades. Para Ball (2011), essas mudanças, que envolvem desde as formas de emprego, sistemas de financiamentos, administração, incluindo as relações sociais, devem ser vistas como integrantes de um processo de mudança mais amplo e globalizado que gradativamente assume um discurso neoliberal, alterando as funções do papel do Estado como agente regulador da economia.

Cabe salientar ainda que essas mudanças contribuem para transformações nos regimes de controle estatal. O Estado passa a incorporar gradativamente a lógica e a cultura do novo gerencialismo, no que se refere a sua ação sobre as políticas educacionais, inserindo nestas princípios mercadológicos de excelência, produtividade, efetividade, qualidade, competitividade, dentre outros. Esses princípios orientaram, a partir da década de 1990, contínuas reformas curriculares no Ensino Médio, em seus princípios orientadores, concepção de currículo, organização curricular e sistemas de avaliação. Silva (2015) afirma que, ao estabelecer uma leitura ampliada desse cenário, é possível inferir que o papel do governo, em uma sociedade neoliberal, está em produzir agenciamentos que ampliem as oportunidades dos sujeitos, ao mesmo tempo em que devem regulamentar o processo competitivo. Este quadro configurado por uma remodelagem nas construções políticas educacionais carrega uma ambiguidade em seu discurso, podendo ser entendido por alguns como significado de maior autonomia da sociedade civil frente à liberação do intervencionismo regulatório do Estado, e por outros, aqui compreendida como a consolidação de uma condição política que tende a conduzir à supremacia do capital.

\section{As diretrizes curriculares para o Ensino Médio a partir de 1990}

Ao situarmos a leitura do cenário educacional brasileiro a partir dos anos de 1990, identificamos reformas curriculares que ganharam força a partir de um 
reordenamento das políticas sociais, calcadas no contexto de descentralização do Estado e nos critérios de eficiência e qualidade, complementadas com a implementação de programas de controle de resultados da performance de alunos e instituições, bem como incremento de parcerias entre Estado-Sociedade (LESSARD, 2016). Esse período de transformações eclodiu no Brasil no governo de Fernando Henrique Cardoso e foi influenciado pela instauração de uma política neoliberal e pela participação dos organismos multilateriais na definição das políticas educacionais, que ganham corpo e concretude no delineamento de documentos normativos que simbolizam a incorporação dessa perspectiva de associação entre educação e sistema produtivo: a Lei de Diretrizes e bases da educação nacional de 1996, as resoluções n. 04/2010 e n. 02/2012 e a lei n. 13.415/2017. Ao abordar o papel dos organismos internacionais nas políticas educacionais, Silva (2015) ressalta que o Banco Mundial e as Agências da Organização das Nações Unidas (ONU) são os principais interlocutores da agenda brasileira. Destaca também que estes organismos ditaram as regras de reestruturação econômica e da globalização, no Brasil e na América Latina, enfatizando um contexto de mercantilização e privatização da educação (SILVA, 2015; SFREDO; SILVA, 2016).

Percebe-se na análise destes documentos, em linhas gerais, a consolidação de perspectivas de caráter prescritivo, orientando a concepção de currículo, o perfil do professor, o trabalho como princípio educativo, as matrizes de referência para ensino e avaliação e, principalmente, a perspectiva da formação do estudante sob perspectivas performáticas e individualizantes (LIMA, 2010).

Em seus artigos e incisos, a LDB 9394/96 apresenta princípios de reordenação da estrutura, dos objetivos e da proposta de formação escolar, nos diferentes níveis, adequando-os ao que se compreendeu como exigências sociais, a saber, característica que definiriam o que se espera do sujeito trabalhador, em seu espaço cultural e sua formação para a cidadania. Em relação ao Ensino Médio, a Lei 9394/96 define que a educação escolar deve estar vinculada ao mundo do trabalho e à prática social e que compete à educação básica possibilitar uma formação comum com vistas ao exercício da cidadania e ao fornecimento dos meios para progredir no trabalho e em estudos posteriores (Art. 22). Identifica-se assim uma associação direta entre reformas e modelo de desenvolvimento econômico na medida em que concebe o currículo,

[...] como resultado de um processo individual de aprendizagem de formas de fazer, definidas pelas necessidades da ocupação a ser exercida, complementada com o desenvolvimento de habilidades 
psicofísicas demandadas pelo posto de trabalho (KUENZER, 2000, p. $31)$.

O trabalho e a cidadania são reapresentados nos documentos que prescrevem a reforma, bem como o indicativo da noção de competência como caminho prescritivo do processo de ensinar e aprender, tendo como referência uma matriz curricular constituída em áreas do conhecimento (RAMOS, 2011; KUENZER, 2000). O Ensino Médio passa assim para a centralidade da agenda educacional, constituindo-se como a última etapa da educação básica destinada a preparar os alunos ao mercado de trabalho ou à continuidade de seus estudos. Os princípios orientadores das distintas resoluções encontram-se em consonância com as orientações das agências multilaterais, dentre elas a UNESCO, pois, a formulação de políticas educativas, particularmente nos países de periferia (e da semiperiferia) do sistema mundial, começou a depender, cada vez mais da legitimação e da assistência técnica das organizações internacionais, o que permitiu, nos anos sessenta, uma rápida difusão das teorias do capital humano e da planificação educacional, núcleo duro das teorias da modernização, tão em voga neste período de euforia, em que a educação se tornou um instrumento obrigatório da autorealização individual, do progresso social e da prosperidade econômica (TEODORO, 2001 p. 127).

Mediante essa perspectiva, o Ensino Médio, através da formação geral, deveria garantir aos alunos o desenvolvimento da capacidade de mobilização de conhecimentos e habilidades que lhes permitiriam gerir suas vidas nas situações a que seriam expostos, notadamente expressos na LDB como "continuidade aos estudos", visto aqui nesta abordagem como uma das finalidades, tendo o seu direcionamento ao ingresso no ensino superior.

A caracterização da atividade de trabalho e das habilidades humanas necessárias para a adaptação às constantes transformações passam a ser os elementos orientadores na elaboração das Diretrizes Curriculares para o Ensino Médio e dos PCNS na década de 1990, tendo a noção competência um dos seus elementos fundamentais. As competências e habilidades assumem a centralidade do processo de ensino aprendizagem, sendo inseridas em inúmeras propostas curriculares nas diferentes unidades da federação (KRAWCZYK, 2011).

Entre os anos de 1995 e 2012 são produzidos vários documentos normativos que, se divergem em sua natureza - ora assumem o caráter de proposta, ora têm uma função normativa - manifestam uma mesma intencionalidade, qual seja, a de produzir mudança significativa na estrutura curricular do ensino médio. Os principais 
documentos oficiais que explicitam essa intenção são os Parâmetros Curriculares Nacionais para o Ensino Médio (PCNEM), produzidos sob orientação do MEC pela sua Secretaria de Educação Média e Tecnológica (SEMTEC); as Diretrizes Curriculares Nacionais para o Ensino Médio (DCNEM), explicitadas na Resolução 3/98 da Câmara de Educação Básica do Conselho Nacional de Educação; e, ainda, as duas formas de avaliação, o Sistema Nacional de Avaliação da Educação Básica (SAEB) e o Exame Nacional do Ensino Médio (ENEM) e mais recentemente as resoluções n. 04/2010 e n. $02 / 2012$.

É fundamental salientar na análise dessas diretrizes o caráter contínuo e progressivo dos princípios da flexibilização e individualização do percurso formativo dos alunos (e também das instituições de ensino). As três resoluções que definem as diretrizes curriculares para o Ensino médio guardam entre si similaridades ao explicitarem em seus artigos e incisos a prescrição de que o processo de ensino e aprendizagem seja desenvolvido a partir de uma matriz de competências e habilidades (PERRENOUD, 1999). A construção de competências sugere a capacidade de mobilização de conhecimentos e habilidades em resposta às situações inusitadas, típicas da transitoriedade e instantaneidade do processo de globalização da economia. Isto responderia à capacidade da multifuncionalidade e da polivalência, necessária aos indivíduos formados pelas escolas para atenderem as demandas do mercado de trabalho. O conhecimento prescrito nos PCNS e nas diretrizes através da definição de áreas do conhecimento, por exemplo, passam a ser o meio ou caminho a ser percorrido por alunos e professores como o intuito de desenvolverem as respectivas habilidades e competências técnicas.

\section{O "novo Ensino Médio" - A premissa máxima do individualismo e da lógica mercadológica}

O Ensino Médio como última etapa da educação básica, como já afirmamos anteriormente, tem recebido ao longo do período de análise deste artigo (1990-2012), uma série de transformações na sua estrutura organizacional e curricular, que mostram uma tendência relacional à conjuntura econômica global. Sob essas condições, Silva (2015) alerta que sob as condições da globalização e da consequente competitividade oriunda deste fenômeno, o campo de seleção e definição dos conhecimentos e da organização curricular, é orientado na lógica da regulação, avaliação e larga escala e 
mobilizada para racionalidades individuais, levando os indivíduos dentro desse contexto a tornarem-se mais competitivos, mobilizando sua vida sob estes princípios.

Tomando como perspectiva a individualização e competitividade nas políticas educacionais contemporâneas, situamos a recente reforma curricular para o Ensino Médio promulgada em fevereiro de 2017, a lei n. 13.415. Esta lei altera sobre cinco dispositivos legais: Lei n. 9.394/1996 - que estabelece as diretrizes e bases da educação nacional, Lei n. 11.494/2007 - regulamenta o financiamento da educação (o Fundeb), o Decreto-Lei n. 5.452/43 - conhecido como CLT, o Decreto-Lei n. 236/1967 que regulou a radiodifusão no país e revoga a Lei n. 11.161/2005, que instituiu o ensino de espanhol obrigatório no ensino médio. O texto aprovado divide o conteúdo do Ensino Médio em duas partes: $60 \%$ para disciplinas comuns a todos, a serem definidas pela Base Nacional Comum Curricular (BNCC), e 40\% para que o aluno aprofunde seus conhecimentos em uma área de interesse, entre as opções Linguagens, Matemática, Ciências Humanas, Ciências da Natureza e Ensino Profissional. Outro pilar da medida provisória é ampliar a oferta de turno integral de 800 horas para 1,4 mil horas anuais, mediante financiamento da União junto aos estados e ao Distrito Federal durante dez anos.

A centralidade da nova reforma no novo currículo é a de que a base comum deve ter tratamento metodológico que assegure a interdisciplinaridade e a contextualização, enquanto a parte diversificada deverá ser organicamente integrada com a base nacional comum, por contextualização que pode ocorrer por enriquecimento, ampliação, diversificação, desdobramento, por seleção de habilidades e competências da base nacional comum e por outras formas de integração. Isso deve ocorrer de acordo com o planejamento pedagógico e curricular da escola. A ideia nessa formulação curricular é que a parte diversificada dê a identidade de cada escola, isto é, defina a vocação de cada escola, pela priorização de uma ou mais áreas do currículo do Ensino Médio.

Ao analisar os artigos e incisos da lei que dá corpo a nova reforma, cumpre destacar os aspectos centrais da reforma que orientarão os sistemas de ensino a promover suas alterações de forma a contemplar os princípios relativos à ampliação da carga horária e à organização curricular: Diante do texto da lei, dois artigos merecem destaque:

Art.35 $\S 7^{\circ}$ - Os currículos do ensino médio deverão considerar a formação integral do aluno, de maneira a adotar um trabalho voltado 
para a construção de seu projeto de vida e para sua formação nos aspectos físicos, cognitivos e socioemocionais.

§ 8- Os conteúdos, as metodologias e as formas de avaliação processual e formativa serão organizados nas redes de ensino por meio de atividades teóricas e práticas, provas orais e escritas, seminários, projetos e atividades on-line, de tal forma que ao final do ensino médio o educando demonstre: I - domínio dos princípios científicos e tecnológicos que presidem a produção moderna;

II - conhecimento das formas contemporâneas de linguagem.

Art. 36. O currículo do ensino médio será composto pela Base Nacional Comum Curricular e por itinerários formativos, que deverão ser organizados por meio da oferta de diferentes arranjos curriculares, conforme a relevância para o contexto local e a possibilidade dos sistemas de ensino [...]

$\S 1$ o A organização das áreas de que trata o caput e das respectivas competências e habilidades será feita de acordo com critérios estabelecidos em cada sistema de ensino (BRASIL, 2017)

$\S 10$. Além das formas de organização previstas no art. 23, o ensino médio poderá ser organizado em módulos e adotar o sistema de créditos com terminalidade específica.

$\S$ 11. Para efeito de cumprimento das exigências curriculares do ensino médio, os sistemas de ensino poderão reconhecer competências e firmar convênios com instituições de educação a distância com notório reconhecimento [...]

$\S 12$. As escolas deverão orientar os alunos no processo de escolha das áreas de conhecimento ou de atuação profissional previstas no caput." (NR)

Os artigos e incisos selecionados acima mostram de forma evidente algumas características que são contínuas nas reformas curriculares implementadas no Ensino Médio desde a década de 1990. Elas evidenciam o aprofundamento do discurso neoliberal em educação, na medida em que expressam premissas de um discurso marcado pela excelência no ensino e na pesquisa; professores competentes; alunos aptos para ingressarem no mercado de trabalho; currículo com conteúdos científicos e tecnológicos atualizados e escolha individualizada do percurso formativo. Num olhar mais atento, a esses princípios apresentados pelo novo projeto de lei, entendemos que representa mais um ponto de vista empresarial do que educacional, visto que traz em seu bojo um raciocínio tecnicista baseado na produtividade e objetivando a performatividade na educação (BALL, 2011; LIMA, 2010; SILVA, 2015).

A "escola de qualidade", pressuposto defendido pelo governo federal, é compreendida como aquela que apresenta um ensino e uma gestão eficiente para competir no mercado, referendando a ideia de que o aluno é um consumidor do ensino e o professor um profissional bem treinado, tendo como principal incumbência preparar os educandos para, mais tarde, se inserirem no mercado de trabalho (LIMA, 2010; 
SFREDO; SILVA, 2016). A homogeneização dos conteúdos, aqui identificada pela opção da obrigatoriedade de Língua Portuguesa, Matemática e Língua Inglesa e a utilização de uma prática pedagógica voltada para o "saber fazer" e a definição de um sistema de avaliação nacional com o objetivo de mensurar o desempenho dos alunos e, consequentemente, do sistema educacional, são ações que visam a garantir o controle e a efetivação da proposta educativa alinhada ao preceitos da lógica econômica globalizante.

A nova proposta de reestruturação curricular do Ensino Médio reforça a perspectiva de que o desenvolvimento econômico do país e seu alinhamento às políticas globais de educação são o caminho a ser percorrido, ao incluir como diretrizes fundamentais: a) a identificação do Ensino Médio com a formação geral básica, articulada com uma perspectiva de educação tecnológica e com o mundo do trabalho; b) o ideário de diversificação e flexibilização curricular, como forma de estabelecer um modelo educacional flexível de atendimento às diferentes clientelas; c) a autonomia da escola e do aluno na adequação curricular, favorecendo o processo formativo contextualizado; d) a definição de matrizes curriculares que privilegiam as competências e as habilidades básicas voltadas para o trânsito e a complementaridade entre o ensino regular e a formação profissional.

A identidade do Ensino Médio, na atual reforma, será constituída pedagogicamente com base em um currículo diversificado e flexibilizado. Esse é considerado o grande eixo das mudanças no Ensino Médio. Socialmente, a identidade do Ensino Médio estará condicionada à incorporação das necessidades locais características dos alunos e participação de professores e famílias na configuração do que é adequado a cada realidade escolar. Parece evidenciar uma intensa lógica de flexibilização, marcada por condições de uma "customização curricular" (SILVA, 2015).

\section{Considerações finais}

O período compreendido entre os anos de 1990 e 2017 assinalaram um intenso conjunto de reformas nas políticas educacionais no Brasil, impactando diretamente sobre a organização curricular do Ensino Médio. Esta etapa da educação básica tem tomado à centralidade das políticas educacionais brasileiras, tendo sua lógica organizativa atrelada às transformações econômicas ocorridas a partir da década de 
1970, tendo como pano de fundo a revolução técnica e científica que desencadeou inúmeras mudanças na esfera produtiva e nas relações econômicas internacionais. Questões como a formação de capital humano, equidade e acesso, competitividade, apresentam-se com ênfases progressivas na análise das legislações que foram produzidas nos últimos anos, revelando elementos que nos levam a compreender a engenharia das reformas curriculares de nosso tempo, que impactam sob os sistemas de ensino de nosso país. Os sujeitos em aprendizagem permanente, a formação com vistas à preparação ao mercado de trabalho e a lógica da individualização no percurso formativo, são conceitos observáveis no conjunto de reformas empreendidas na análise deste artigo, nas seções deste texto, que analisaram a conjuntura de reordenamento educacional que o Ensino Médio sofreu nas últimas décadas.

Atenta-se que, a partir da segunda metade do século $\mathrm{XX}$, em função do reordenamento das forças produtivas e das lógicas de reprodução do capital, a educação passa a ser vista como a engrenagem necessária para impulsionar o pêndulo da economia. Continuamente, observa-se o alinhamento das políticas educacionais às lides do mercado, que juntamente com os organismos internacionais passam a direcionar receituários que se constituem marcos de regulação para que os Estados passem a operacionalizar mudanças em seus sistemas de ensino. Procuramos, no escopo deste artigo, explicitar como a dinâmica do sistema capitalista e as novas funções que o Estado moderno assume, incorporam continuamente na agenda educacional princípios ou lógicas do mercado, tais como eficiência, a responsabilização e a qualidade total, que são incorporados nas diretrizes e legislações com o intuito de alinhar o percurso formativo dos estudantes à lógica empresarial. O Brasil incorpora essa agenda a partir da década de 1990, e vê-se pela análise da legislação e contínuas reformas educacionais, a adequação das políticas educacionais aos preceitos do mercado. É tênue essa ligação, percebendo-se que desde o advento da mais recente LDB, lei n. 9394/96, a flexibilização é um imperativo contínuo, prevendo amplas possibilidades organizativas de currículo, organização de percursos formativos do alunado e um sistema de responsabilização para escolas e sistemas de ensino. No âmbito curricular, no Ensino Médio, evidencia-se um deslocamento para a formação de um indivíduo dotado de habilidades e competências, capaz de se adequar com facilidade a novas e contínuas situações. Em nossa leitura, importa enaltecer, a principal consequência deste cenário é a constituição de um indivíduo responsabilizado pela sua própria formação. 


\section{REFERÊNCIAS}

ANTUNES, Ricardo.; PINTO, Geraldo. A fábrica da educação: da especialização taylorista à flexibilização toyotista. São Paulo: Cortez, 2017.

BALL, Stephen.; MAINARDES, Jefferson (orgs.) Políticas educacionais: questões e dilemas. São Paulo: Cortez, 2011.s

BRASIL. Lei n. ${ }^{\circ}$ 9.394, de 20 de dezembro de 1996. Estabelece as diretrizes e bases da Educação Nacional. Disponível em:

<http://www.planalto.gov.br/ccivil_03/leis/L9394.htm>. Acesso em: 12 abr. 2017

BRASIL. Conselho Nacional de Educação. Resolução no 04 de 13 de Julho de 2010. Define diretrizes curriculares para a Educação Básica. Disponível em:

<http://portal.mec.gov.br/dmdocuments/rceb004_10.pdf>. Acesso em: 12 abr. 2017.

BRASIL. Conselho Nacional de Educação. Resolução no 02 de 30 de janeiro de 2012. Define diretrizes curriculares nacionais para o Ensino Médio. Disponível em:

<http://pactoensinomedio.mec.gov.br/images/pdf/resolucao_ceb_002_30012012.pdf>. Acesso em: 12 abr. 2017.

BRASIL. Lei no 13.415 de 16 de fevereiro de 2017. Estabelece política de fomento a implementação de escolas de ensino médio em tempo integral. Diário oficial da União, Brasília, DF, 17 de fevereiro de 2017. Disponível em:

<www.planalto.gov.br/ccivil_03/_ato2015-2018/2017/lei/L13415.htm>. Acesso em: 12 abr. 2017.

CASTELLS, Manuel. A sociedade em rede. São Paulo: Paz e Terra, 1999.

HARVEY, David. Condição Pós-Moderna: uma pesquisa sobre as origens da mudança cultural. Tradução Adail U. Sobral e Maria S. Gonçalves. São Paulo: Loyola. 1993.

HARVEY, David. Espaços de esperança. Tradução Adail U. Sobral e Maria S. Gonçalves. $2^{a}$ edição. São Paulo: 2006.

IANNI, Octavio. Globalização: novo paradigma das ciências sociais. Estud. av., ago. 1994 , v. 8 , n. 21 , p. $147-163$.

KRAWCZYK, Nora. Reflexão sobre alguns desafios do ensino médio no Brasil hoje. Cadernos de Pesquisa, São Paulo, v. 41, n. 144, p. 752-769, set./dez., 2011.

KUENZER, Acácia Zeneida. O ensino médio agora é para vida: entre o pretendido, o dito e o feito. Ed. Soc, v. 21, n. 70, p. 15-39, 2000.

LESSARD, Claude. Políticas educativas: a aplicação na prática. tradução de Sthephania Motousek. Petrópolis, RJ, Vozes, 2016.

LIMA, Licínio. A educação faz tudo? Crítica ao pedagogismo na sociedade de aprendizagem. Revista Lusófona de Educação, n. 15, p. 41-54, 2010. 
PERRENOUD, Phillipe. Avaliação: da excelência à regulação das aprendizagens, entre duas lógicas. Porto Alegre: Artmed, 1999.

POPKEWITZ, Thomas. Reforma educacional: uma política sociológica- poder e conhecimento em educação. Tradução Beatriz Affonso Neves. Porto Alegre, Artes Médicas, 1997.

POPKEWITZ, Thomas. Reforma, conhecimento pedagógico e administração social da individualidade: a educação escolar como efeito de poder. In: IMBERNÓN, Francisco (org.). A educação no século XXI: os desafios do futuro imediato. Porto Alegre: Artmed, 2000. p. 141-70.

RAMOS, Marise Nogueira. O ensino médio ao longo do século XX: um projeto inacabado. In: STEPHANOU, Maria.; BASTOS, Maria Helena Câmara (orgs.). Histórias e memórias da educação no Brasil: século XX. 4. ed. Petrópolis: Vozes, 2011. v. III, p. 229-241.

SANTOS, Milton. A natureza do espaço: técnica e tempo- razão e emoção. São Paulo: Hucitec, 1999.

SANTOS, Milton. Da totalidade ao lugar. São Paulo: Edusp, 2005

SANTOS, Milton. Metamorfoses do espaço habitado. São Paulo: Hucitec, 1996.

SANTOS, Milton. Espaço e método. São Paulo: Nobel, 1985

SANTOS, Milton. Espaço e sociedade. Petrópolis: Vozes, 1980.

SANTOS, Milton. Por uma nova geografia. $6^{\text {a }}$ ed. $1^{\text {a }}$ reimpressão. São Paulo: Edusp, 2008,

SANTOS, Milton. Modo de produção técnico-científico e diferenciação espacial. Revista Território, Ano IV, nº 6, jan/jun., 1999.

SANTOS, Milton.; Silveira, Maria Laura. O Brasil: território e sociedade no início do século XXI. $9^{\text {a }}$ ed. Rio de Janeiro: Record, 2006.

SAVIANI, Demerval. Apresentação. In: GASPARIN, João Luíz. Uma didática para a pedagogia histórico-crítica. Campinas: Autores Associados, 2002a. p. IX-XII.

SFREDO, Marta.; SILVA, Roberto Rafael Dias da. Políticas educacionais para o Ensino Médio: conhecimento ou capacitação. Práxis Educativa, v. 11, n. 3, p. 881-896, 2016.

SILVA, Roberto Rafael Dias da. Políticas de constituição do conhecimento escolar para o ensino médio no Rio Grande do Sul: uma analítica de currículo. Educação em revista, v. 30, n. 1, p. 127-158, 2014.

TEODORO, António. Organizações internacionais e políticas educativas nacionais: a emergência de novas formas de regulação transnacional, ou uma globalização de baixa intensidade. In: STOER, Stephen.; CORTESÃO, Luiza; CORREIA, José Alberto 
(orgs.). Transnacionalização da Educação: da crise da educação à “educação" da crise. Porto, Portugal: Edições Afrontamento, 2001.

\section{Como citar este artigo:}

SILVEIRA, Emerson Lizandro Dias.; SILVA, Roberto Rafael Dias da. A flexibilização como um imperativo político nas políticas curriculares para o Ensino Médio no Brasil: uma leitura crítica. Revista Ibero-Americana de Estudos em Educação, Araraquara, v. 13, n. 4, p. 1759-1778, out./dez., 2018. E-ISSN: 1982-5587. DOI: 10.21723/riaee.unesp.v13.n4.out/dez.2018.11226

Submissão em: 22/03/2018

Revisões requeridas: 28/04/2018

Aprovação final em: 25/05/2018 
RIAEE - Revista Ibero-Americana de Estudos em Educação, Araraquara, v. 13, n. 4, p. 1759-1778, out./dez., 2018. 